International Journal of Biotechnology and Biochemistry

ISSN 0973-2691 Volume 13, Number 1 (2017) pp. 39-47

(C) Research India Publications

http://www.ripublication.com

\title{
Extraction and Characterization of Pectin from Orange Peels
}

\author{
Alok Kumar Tiwari*, Samarendra Nath Saha, Vishnu Prasad Yadav, Uttam \\ Kumar Upadhyay, Deepshikha Katiyar, Tanya Mishra \\ Guru Ghasidas Vishwavidyalaya (A Central University), \\ Institute of Technology, Department of Chemical Engineering, \\ Bilaspur, Chhattisgarh, 495009, India.
}

\begin{abstract}
The sweet oranges (Citrus sinensis (L.)) are a very commonly growing tree fruit in the world. The present work explores the possibility of separation of essential oils and pectin from the orange peels. It is found from the experimental observations that the peel source, for extraction of pectin, when taken after extracting orange oil through simple distillation gives higher yield than leaching residue [1]. This work uses Soxhlet extraction for the extraction of oil and the pectin is extracted by acid extraction method from the remaining peels. Strong acids are corrosive and may be a potential threat to health. Moreover, the liquid waste generated from the industrial processes might lead to burden the environment and a high cost might incur for treating the strong acidic waste [2]. Varying $\mathrm{pH}$ solutions of citric acid are used for the pectin extraction. The effect of $\mathrm{pH}$ of the acid solutions and mesh size of the orange peels on pectin yield and composition was studied in a citric acid extraction process. The pectin yield and degree of esterification (DE) of the extracted pectin ranged from 7.3 to $52.90 \%$ and 5.1 to $71.0 \%$ respectively. It was found that extraction $\mathrm{pH}$ was the most important parameter influencing yield. These results demonstrate the successful extraction of essential oil and pectin, providing potential benefits for industrial extraction of pectin from an economic and environmental point of view.
\end{abstract}

Keywords: Orange peels, $\mathrm{pH}$, pectin, Soxhlet extraction, degree of esterification, yield. 


\section{INTRODUCTION:}

Citrus fruits are at the top not only in total production, but also in economic value. One of them; oranges, specifically, the oranges (Citrus sinensis (L.)) are a very commonly growing tree fruit in the world. Oranges are widely cultivated in tropical and subtropical climates, which is peeled and eaten whole, or processed to extract orange juice and also for the fragrance. These essential oils (fragrance) are a mixture of volatile compounds as terpenes and oxygenated derivatives such as aldehydes (citral), alcohols and esters [3]. They have a great commercial importance and various applications in many food industry products because of their aroma and functional properties (antifungal, antimicrobial, etc.) which make them excellent additives. The present work explores the possibility of separation of essential oils and pectin from the orange peels.

Pectin is a natural, biocompatible, biodegradable and renewable polysaccharide characterized as an emulsifier, gelling agent, glazing agent, stabilizer, and/or thickener in commercial applications; all of which are in fact subsets of the term -rheology modifier [2-4]. Pectin gels are formed when the molecule chains are cross-linked, forming a three-dimensional network where water and co-solutes are retained [5].

Consumption of pectin has been shown to reduce blood cholesterol levels. In the large intestine and colon, microorganisms degrade pectin and liberate short-chain fatty acids that have positive influence on health [6].

The Joint FAO/WHO Expert Committee on Food Additives (JECFA) has recommended pectin as a safe additive with no limit on acceptable daily intake [7]. Pectin is quite stable under the acidic condition of the stomach, although a slight deesterification can occur. Without the fermentation process, pectin would pass almost unchanged through the digestive system [8]. Increasing consumer awareness of a healthy lifestyle and the emerging trend to produce functional food has made pectin popular. It has been reported that pectin has numerous positive influences on health including improving colonic health, lowering of cholesterol and serum glucose levels, reducing cancer propensity, and stimulating the immune response [9]. The degree of methyl-esterification (also known as degree of methylation) (DM) of GalA units is used to classify pectin. DM is a percentage which expresses the molar ratio of methylesters present to GalA units (includes both free GalA and substituted GalA) [10]. It is the major parameter affecting gelling, influencing surface tension and emulsion formation.

The DM percentage above $50 \%$ is classified as high methyl ester (HM) pectin while those less than $50 \%$ is known as low methyl ester (LM) pectin [11]. The lower the $\mathrm{DM}$, the faster pectin is hydrolysed, probably due to a lower amount of methylesterified target groups. This in turn influences gel strength, leading to the formation of a weaker gel [12]. However, at controlled or reduced temperatures, there is a higher possibility that LMP will be obtained without extensive main-chain breakdown. Enzyme de-esterification has becoming increasingly popular for obtaining LMP in an efficient and environmentally sustainable manner [13, 14]. 
Rapid-setting HMP is usually obtained after a short extraction time at temperatures close to boiling [15]. This is due to short extraction times with high temperature reduces de-esterification. Conversely, long extraction times with low temperature favour slow-setting HMP or even LMP. Therefore, it is important to select suitable extraction conditions to obtain pectin with the desired properties $[16,17]$.

This work aims to extract and characterize pectin from orange peels using citric acid at various $\mathrm{pH}$.

\section{MATERIALS AND METHODS:}

\section{Chemicals}

Citric Acid- 99.5\% pure, Sodium hydroxide- 0.09-0.11 N (Concentration), Phenolphthalein- 0.1\% w/v, Ethanol-99.9\% pure, Hydrochloric Acid - 0.1 $\pm 0.0005 \mathrm{~N}$, Petroleum ether- $99.5 \%$ pure.

This work is divided into two parts: (a) Separation of essential oil (b) Extraction of pectin

\section{Separation of essential oil}

Orange essential oil is present in small ductless gland contained in the peel of the orange fruits. The main constituent of orange peel essential oil is d-limonene (present to the extent of at least $90 \%$ ), which is the only hydrocarbon present [18, 19]. Distillation is the most widely used method to produce essential oils. In this work the Soxhlet Extraction method has been adopted ensuring no alteration in the properties of the components and greater yield with appreciable solvent recovery.

\section{Extraction of pectin}

Extraction is the most important process in the pectin production. Pectin extraction in a hot diluted strong mineral acid solution is the most commonly used method [19]. Strong acids are corrosive and may be a potential threat to health. Moreover, the liquid waste generated from the industrial processes lead to burden the environment and a high cost might incur for treating the strong acidic waste [20,21].

This work takes into account different variations starting with the size of the crushed orange peels followed by the time of extraction and the $\mathrm{pH}$ values of the acidic solution used for the extraction of pectin.

The orange peels are sun dried till their moisture content is negligible. They are then crushed and 16, 32 and 60 mesh screens are used to separate the powdered peels accordingly. 80 gms of powdered peel of 16 mesh size is taken and fed to the Soxhlet apparatus with $1000 \mathrm{~mL}$ of petroleum ether (taken as solvent). The setup is maintained at $40^{\circ} \mathrm{C}$ (B.P. of Petroleum ether) for 6 hours, 9 hours and 12 hours respectively. The oil collects at the bottom in the solvent which can be separated by simple distillation. 
Further, the powdered peels are collected separately after the solvent extraction is complete.

Citric acid solutions of $\mathrm{pH} 1.0,1.5,2.0$ and 2.5 are prepared. $5 \mathrm{gms}$ of powdered peels collected are heated with the $\mathrm{pH}$ solutions prepared for 30 minutes (optimum time) at temperature $65^{\circ} \mathrm{C}$ with continuous stirring. After cooling the solution, it was filtered with muslin cloth. The filtrate was added to double amount of ethanol and allowed to precipitate. The jelly-like precipitate formed is nothing but pectin which was subsequently washed with ethanol two times. Pectin was then dried in a hot air oven at $40^{\circ} \mathrm{C}$ for 20 minutes. The process was repeated for 32 and 60 mesh size Fig. 1.

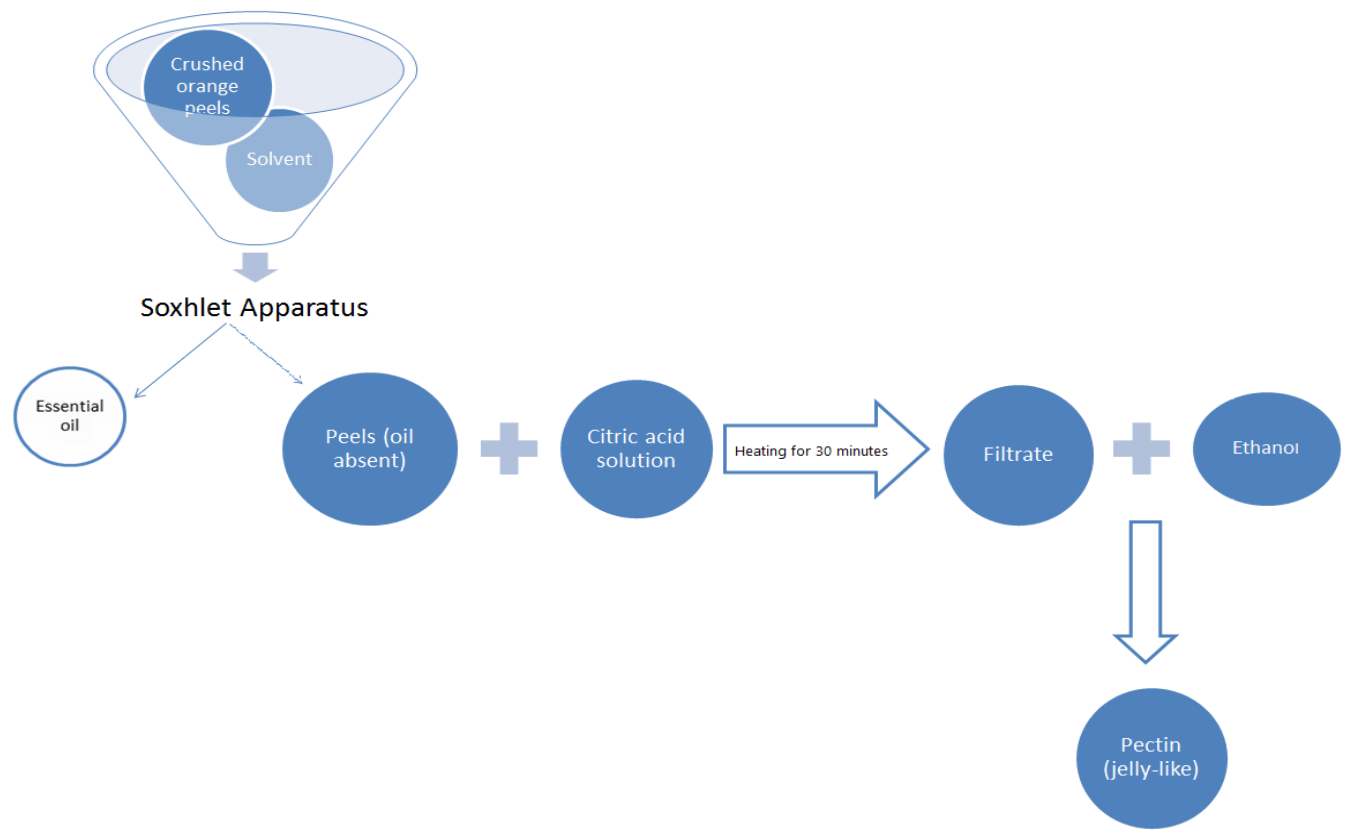

Fig 1: Flow sheet for the acid extraction of pectin

Now, the pectin yield can be calculated as:

$$
\text { Yield }(\%)=\frac{\text { Amount of dry pectin obtained }(\mathrm{g})}{\text { Amount of orange powder taken }(\mathrm{g})} * 100
$$

The degree of esterification, DE is defined as the ratio of esterified galacturonic acid groups to the galacturonic acid groups present [22]. $0.2 \mathrm{~g}$ of dried pectin sample was moistened with ethanol and dissolved in $20 \mathrm{ml}$ distilled water. Three drops of phenolphthalein were added into the sample. The sample was titrated with $0.1 \mathrm{~N}$ sodium hydroxide. The result was recorded as the initial titration volume once some pink colour appeared. The number of free carboxy group was calculated from the volume of $0.1 \mathrm{~N}$ sodium hydroxide solution spent for initial titration. $10 \mathrm{ml}$ of $0.1 \mathrm{~N}$ sodium hydroxide was added to neutralize polygalacturonic acid. The sample was 
plugged with a stopper and shaken vigorously, then allowed to stand at room temperature for 2 hours to de-esterify pectin. $10 \mathrm{ml}$ of $0.1 \mathrm{~N}$ hydrochloric acid was added to neutralize sodium hydroxide and the sample was shaken until its pink colour disappeared. Three drops of phenolphthalein were added into the sample and the sample was further titrated with $0.1 \mathrm{~N}$ sodium hydroxide. The volume of titration was recorded as final titration volume once some pink colour appeared. The number of the esterified carboxy group was calculated from the volume of $0.1 \mathrm{~N}$ sodium hydroxide solution spent for final titration [23]. The degree of esterification can be calculated as:

$$
D E(\%)=\frac{\text { Final titration volume }(\mathrm{ml})}{\text { Intital titration volume }(\mathrm{ml})+\text { Final titration volume }(\mathrm{ml})} * 100
$$

\section{RESULTS AND DISCUSSIONS:}

\section{Degree of Esterification}

The influence of $\mathrm{pH}$ on Degree of Esterification was studied in a citric acid extraction process. As seen from the Fig $2(a, b, c)$, at low $\mathrm{pH}(<2.0)$ Low Methoxyl(LM) pectin is formed whereas at $\mathrm{pH}>2.0$, High Methoxyl (HM) pectin is formed. LM Pectin will form a thermo- irreversible gel, which means that it will stay gelled even when heated to temperatures that would normally melt it [24]. High Methoxyl pectin is the form of pectin traditionally used for canning applications. It requires high amounts of sugar to gel and is very sensitive to acidity [25]. Low Methoxyl pectin has been used in the food industry to create low-sugar jams because it does not require high sugar levels to gel and has become popular for pastries and molecular recipes designed not to be as sweet [26]. Low Methoxyl pectin is used as a gelling agent, thickening agent and stabilizer. Low Methoxyl pectin can also be used as a fat substitute in baked goods and to stabilize acidic protein drinks such as drinking yogurt [27].

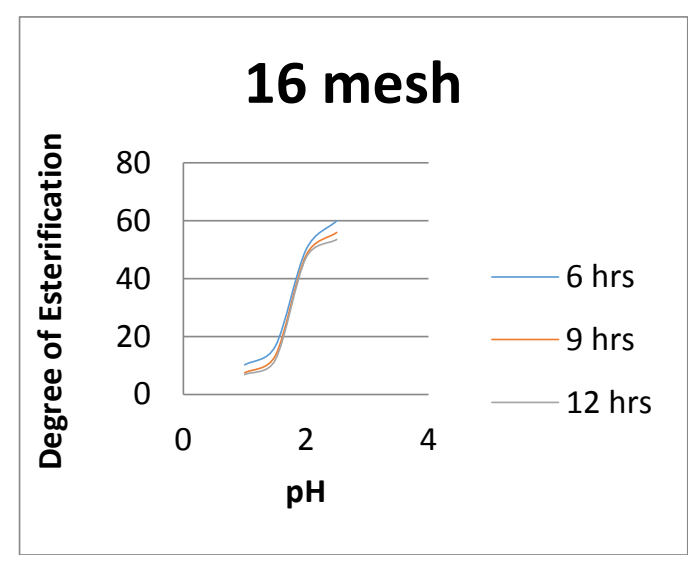

(a)

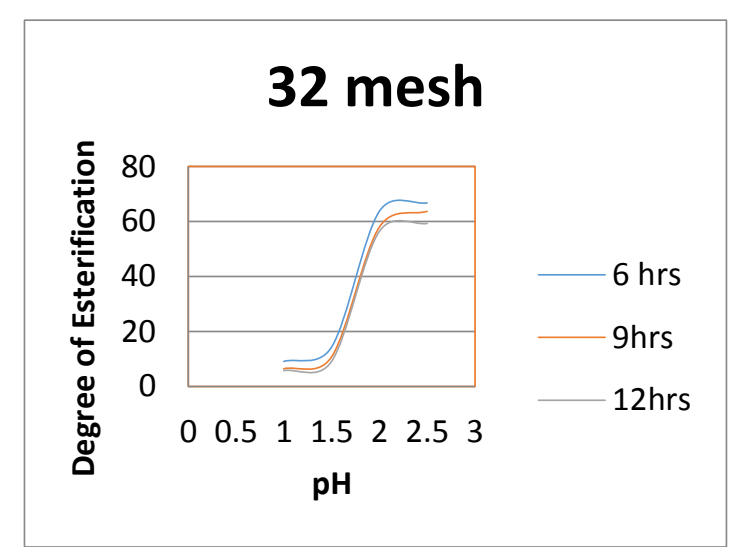

(b) 


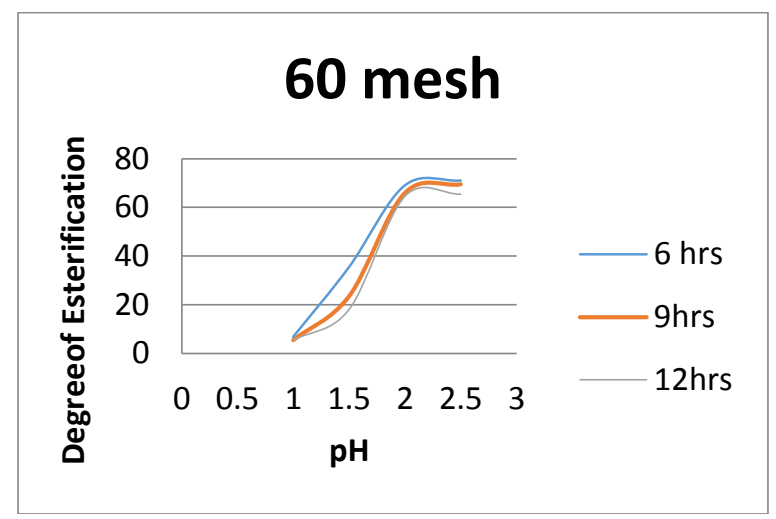

(c)

Fig 2: Variation of Degree of esterification w.r.t $\mathrm{pH}$ at 6, 9 and 12 hours of Soxhlet run time with orange peels of mesh size (a) 16, (b) 32, (c) 60

\section{Yield}

$\mathrm{pH}$ is considered as one of the more crucial parameters affecting the amount and properties of extracted pectin. Fig. 3 shows that pectin yield decreased with increasing $\mathrm{pH}$, highest being $52.90 \%$ at $\mathrm{pH} 1$ and 60-mesh size. The presence of high concentration of hydrogen ions in the solvent has stimulated the hydrolysis of protopectin [28-30]. At low $\mathrm{pH}$, as the hydrogen ion concentration of the solution is increased, ionization of the carboxylate groups is repressed, i.e., the highly hydrated carboxylate group is converted into hydrated carboxylic acid groups [31, 32]. The loss of carboxylate groups is able to reduce the repulsion of the polysaccharide molecules which promotes the gelation properties of pectin giving more precipitated pectin at lower $\mathrm{pH}$ [33]. This observation agreed with previous work who extracted pectin from apple pomace and sugar beet pulp where the yield increased with increasing acid strength. Further, increase in the yield of pectin is also noted as the size of the powdered peels decreased $[11,34]$. This happens as the surface area available for mass transfer increases with the decreasing size thus increasing the yield [35].

\section{CONCLUSIONS:}

The present work revealed that the sweet orange peels are good source of orange oil and pectin and does have the potential to become important raw material for food processing industries. The maximum pectin yield is $52.90 \%$ clearly represented by the Fig. 3. The degree of esterification varies from 5.1 to $71.0 \%$ according to $\mathrm{pH}$ and mesh sizes as shown in fig. 2(a, b, c). The process in which essential oil is first extracted followed by acid extraction of pectin is most suitable for industrial production. These results demonstrate the successful extraction of essential oil and pectin, providing potential benefits for industrial extraction of pectin from an economic and environmental point of view. 


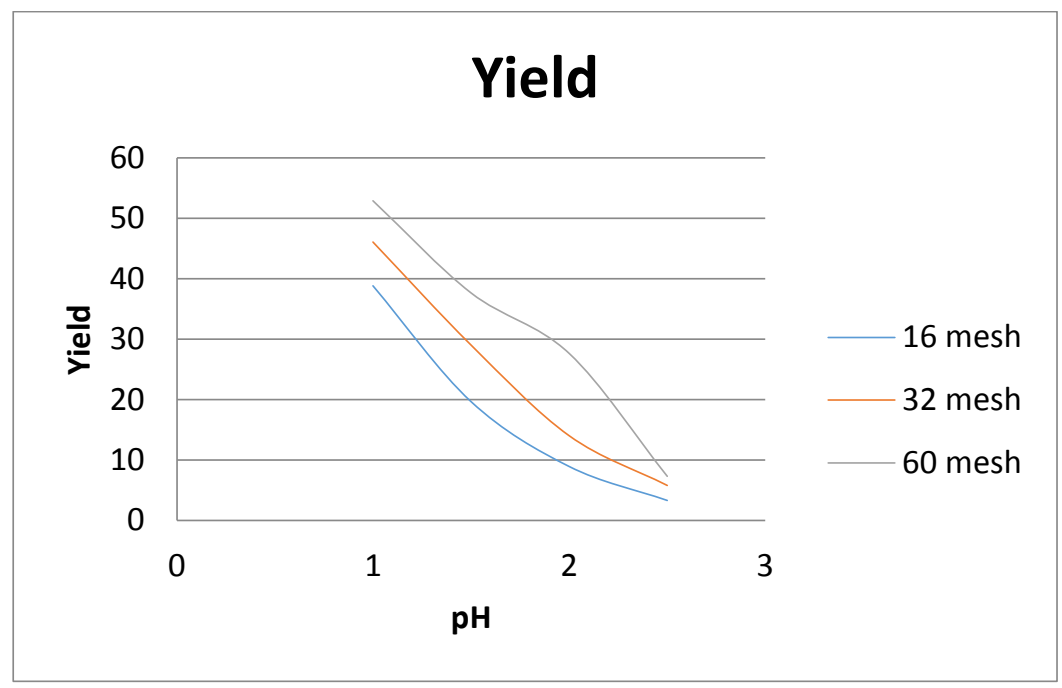

Fig 3: Variation of yield of pectin extracted from 16, 32 and 60 mesh size peels w.r.t pH.

\section{ACKNOWLEDGEMENTS:}

The authors are grateful to the Department of Chemical Engineering for providing the infrastructural facilities. The authors also wish to thank Dr. Sanjay Kumar Lanjhiyana and Dr. K. Kesavan (Department of Pharmacy) and Dr. V. K. Rai (Department of Chemistry) for their valuable assistance in the direction of the completion of this research work.

\section{REFERENCES:}

[1] Pandharipande S., Makode H., 2012, "Separation of Oil and Pectin from Orange Peel and Study of Effect Of pH Of Extracting Medium on the Yield of Pectin," Journal of Engineering Research and Studies, 3(2), pp. 06-09.

[2] Chin N. L. et al., 2014, "Extraction and Characterization of Pectin from Passion Fruit Peels," Agriculture and Agricultural Science Procedia, 2, pp. 231 $-236$.

[3] Bustamante J. et al., 2016, "Microwave assisted hydro-distillation of essential oils from wet citrus peel waste," Journal of Cleaner Production, 137, pp. 598605.

[4] Williams M. A. K. et al., 2009, "Determining the degree of methylesterification of pectin by ATR/FT-IR: Methodology optimisation and comparison with theoretical calculations," Carbohydrate Polymers, 78, pp. 847-853.

[5] Lima M. S. et al., 2014, "Fruit pectins - A suitable tool for screening gelling properties using infrared spectroscopy," Food Hydrocoll., 24, pp. 1-7. 
[6] Tang P.Y. et al., 2011, "Optimization of Pectin Extraction from Peel of Dragon Fruit (Hylocereus polyrhizus)," Asian Journal of Biological Sciences, 4, pp. 189-195.

[7] Karki B. et al., 2010, "Enhancing protein and sugar release from defatted soy flakes using ultrasound technology," J. Food Eng., 96 (2), pp. 270-278.

[8] BeMiller J. N., 1986, "An Introduction to Pectins: Structure and Properties, Chemistry and Function of Pectin," American Chemical Society, pp. 2-12.

[9] Mort A. J. et al., 1993, "Determination of the pattern of methyl esterification in pectin," Distribution of contiguous nonesterified residues, Carbohydr., 247, pp.21-35.

[10] Monsoor M. A. et al., 2001, "Determination of polygalacturonic acid content in pectin extracts by diffuse reflectance Fourier transform infrared spectroscopy," Food Chem, 74, pp. 233-238.

[11] Yapo B.M. et al., 2007, "Effect of Extraction Conditions on the Yield, Purity and Surface Properties of Sugar Beet Pulp Pectin Extracts," Journal Food Chemistry, 100, pp. 1356-1364.

[12] Choo W. S. et al., 2017, "Pectin as a Rheology Modifier: Origin, Structure, Commercial Production and Rheology," Carbohydrate Polymers, 161, pp. 118-139.

[13] Chan S. Y., Choo W. S., 2013, "Effect of extraction conditions on the yield and chemical properties of pectin from cocoa husks," Food Chem, 141, pp. 3752-3758.

[14] Thompson I. P. et al., 2010, "Biorefinery of waste orange peel," Crit. Rev. Biotechnol, 30 (1), pp. 63-69.

[15] Pilnik W., Reitsma J. C. E., 1989, "Analysis of mixtures of pectins and amidated pectins," Carbohydrate Polymers, 10(2), pp. 315-319.

[16] Xue Z. H. et al., 2011, "Optimization of Pectin Extraction from Citrus Peel by Response Surface Methodology,” Food Science, 18, pp. 128-132.

[17] Maran J. P. et al, 2017, "Ultrasound Assisted Extraction of Pectin From Waste Artocarpus Heterophyllus Fruit Peel," Ultrasonics Sonochemistry, 34, pp. 525530.

[18] Lopresto C. G. et al., 2014, "A non-conventional method to extract d-limonene from waste lemon peels and comparison with traditional soxhlet extraction," Separation and Purification Technology, 137, pp. 13-20.

[19] Qilong R. et al., 2013, "Recent Advances in Separation of Bioactive Natural Products," Chinese Journal of Chemical Engineering, 21, pp. 937-952.

[20] Khule N. R. et al., 2012, "Extraction of pectin from citrus fruit peel and use as natural binder in paracetamol tablet," Der Pharmacia Lettre, 4(2), pp.558-564.

[21] Pereira P. H. F. et al., 2016, "Pectin extraction from pomegranate peels with citric acid," International Journal of Biological Macromolecules, 88, pp. 373379.

[22] Filippov M. P., Shkolenko G. A., Kohn R., 1978, "Determination of the esterification degree of the pectin of different origin and composition by the method of infrared spectroscopy," Chem. Zvesti, 32(2), pp. 218-222. 
[23] Lin T. P. et al., 1990, "Quantification of Methyl Ester Content of Pectin by Pectinesterase," Academia Sinica, 31, pp. 273-278.

[24] Yapo B. M., Koffi K. L., 2014, "Extraction and Characterization of Highly Gelling Low Methoxy Pectin from Cashew Apple Pomace," Foods, 3, pp. 112.

[25] Pinheiro E. R. et al., 2008, "Optimization of Extraction of High-Ester Pectin from Passion Fruit Peel (Passiflora edulis Flavicarpa) with Citric Acid by using Response Surface Methodology," Bioresourse. Technology, 99, pp. 5561-5566.

[26] Pan Z. et al., 2011, "Continuous and pulsed ultrasound-assisted extractions of antioxidants from pomegranate peel," Ultrason. Sonochem., 18, pp. 12491257.

[27] Marcon M. V. et al, 2005, "Pectins from apple pomace", Ciência e Tecnologia, 15(2), 127-129.

[28] Dixon D. W. et al., 2008, "Characterization of Commercial Pectin Preparations Spectroscopic and Chromatographic Techniques," Electronic Theses and Dissertations, pp. 1910.

[29] Chen R. W. et al., 1998, "Pectinesterase and pectin complexes inhibit ion exchange membrane separation," J. Agric. Food Chem., 46(5), pp. 1777-1782.

[30] Sun B. et al., 2017, "An organic nonvolatile resistive switching memory device fabricated with natural pectin from fruit peel," Organic Electronics, 42, pp. 181-186.

[31] Sereewatthanawut I. et al., 2008, "Extraction of protein and amino acids from deoiled rice bran by subcritical water hydrolysis," Bioresource Technol., 99 (3), pp. 555-561.

[32] Emaga T. H. et al., 2008, "Characterisation of pectins extracted from banana peels (Musa AAA) under different conditions using an experimental design," Food Chem, 108, pp. 463-471.

[33] Agarwal P. C., Pruthi J. S., 1968, "A Study of Factors Governing the Recovery and Quality of Pectin from Fresh Mandarin Orange Waste (Peel and Pomace)," Indian Food Packer, 22(3), pp. 5-9.

[34] Fertonani H. C. R. et al., 2005, "Extraction of Pectin from Apple Pomace," Brazilian Archives of Biology and Technology, 48, pp. 259-266.

[35] Poletto M., Reverchon E., 1996, "Comparison of models for supercritical fluid extraction of seed and essential oils in relation to the masstransfer rate," Ind. Eng. Chem. Res., 35 (10), pp. 3680-3686. 
